\begin{tabular}{|c|l|}
\hline Title & Is methylene blue an appropriate substrate for a photocatalytic activity test? A study with visible light responsive titania \\
\hline Author(s) & Y an, Xiaoli; Ohno, Teruhisa; Nishijima, Kazumoto; A be, Ryu; Ohtani, Bunsho \\
\hline Citation & $\begin{array}{l}\text { Chemical Physics Letters, 429(4-6), 606-610 } \\
\text { https://doi.org/10.1016/.cplett.2006.08.081 }\end{array}$ \\
\hline Issue Date & $2006-10$-05 \\
\hline Doc URL & http://hdl.handle.net/2115/14893 \\
\hline Type & article (author version) \\
\hline File Information & CPL429-46.pdf \\
\hline
\end{tabular}

Instructions for use 


\title{
Is methylene blue an appropriate substrate for a photocatalytic activity test? A study with visible-light responsive titania
}

\author{
Xiaoli Yan ${ }^{\mathrm{a}}$, Teruhisa Ohno ${ }^{\mathrm{b}}$, Kazumoto Nishijima ${ }^{\mathrm{b}}$, Ryu Abe ${ }^{\mathrm{a}}$, Bunsho Ohtani ${ }^{\mathrm{a}, *}$ \\ ${ }^{a}$ Catalysis Research Center, Hokkaido University, Kita-ku N21W10, Sapporo 001-0021, Japan \\ ${ }^{\mathrm{b}}$ Department of Material Science, Faculty of Engineering, Kyushu Institute of Technology, 1-1 \\ Sensuicho, Tobata, Kitakyushu 804-8550, Japan
}

Received 20 July 2006; in final form 15 August 2006

\section{Abstract}

An analysis of decomposition of methylene blue (MB) in an aerated aqueous solution by its action spectrum has shown that sulfur-doped titania $\left(\mathrm{S}-\mathrm{TiO}_{2}\right)$ has activity under visible-light irradiation and that the decomposition mechanism depends on the excitation wavelength. This suggests that photosensitive materials are not suitable as probe chemicals for photocatalytic activity tests, especially those for evaluation of activity under visible light. It is confirmed using acetic acid instead of $\mathrm{MB}$ that $\mathrm{S}-\mathrm{TiO}_{2}$, but not ordinary non-doped titania, leads to the photocatalytic reaction under visible radiation below $600 \mathrm{~nm}$, which corresponds to its absorption spectrum.
*Corresponding author. FAX: +81-11-706-9133; TEL: +81-11-706-9132.
E-mail address: ohtani@cat.hokudai.ac.jp (B. Ohtani). 


\section{Introduction}

Titania $\left(\mathrm{TiO}_{2}\right)$ photocatalysts have been used widely for various practical applications [1,2]. Current efforts have been focused on their modification to extend the wavelength of photoabsorption towards the visible region that matches the solar spectrum or indoor illumination. Attempts have been made along this line on doping with transition metals $[3,4]$ and metal complexes [5], semiconductor coupling [6,7], and hydrogen reduction [8,9]. Doping with non-metallic elements such as nitrogen [10-15], fluorine [16], carbon [17-19], boron [20], sulfur [21-23], or their mixture [24-26], has also been tested. As expected from their yellow or orange color, these modified $\mathrm{TiO}_{2} \mathrm{~S}$ have visible absorption. Nevertheless, an increase in visible absorption, in principle, does not guarantee visible-light induced activity; since photocatalytic reactions proceed through redox reactions by photogenerated positive holes and photoexcited electrons. No activity may be observed if, for example, all of these species recombine. Various activity evaluation systems with different probe materials or indicators have been reported. Dyes are commonly used as model pollutants, partly because their concentration can be easily monitored using a spectrometer. However, as dyes also absorb light, especially in the visible range, the influence of this photoabsorption by dyes should be excluded for evaluation of the real photocatalytic activity of photocatalysts.

In the present paper, we report action spectra, i.e., plots of photochemical reaction rate or yield per unit number of incident photons as a function of the wavelength. The suitability of methylene blue (MB) [27-29] has been studied as a representative dye for systems of activity evaluation by comparison with the test on decomposition of acetic acid $(\mathrm{AcOH})$ in its aerated suspension system. We have determined by this analysis of action spectra which substances, e.g., anatase and rutile crystallites, absorb light to induce photocatalytic reactions [30].

\section{Experimental}




\subsection{Materials}

Two model photocatalysts of titania samples, home-made sulfur-doped $\mathrm{S}-\mathrm{TiO}_{2}$ and a commercial sample (Nippon Aerosil P-25) as a reference, were chosen. The latter was used without pre-treatment or modification before use. $\mathrm{S}-\mathrm{TiO}_{2}$ was prepared from titanium(IV) tetraisopropoxide and thiourea; details of the synthesis and properties have been reported [23]. While Sakthivel et al. reported that titania particles prepared in a similar way contained no sulfur [12], appreciable doping of sulfur was observed in the present sample. The origin of visible-light photoactivity is not discussed here, since it has no effect on the conclusion of this paper.

\subsection{Monochromatic photoirradiation}

Photocatalytic decomposition of MB (Wako Pure Chemical, $0.05 \mathrm{mmol} \mathrm{dm}^{-3}$ ) in an aerated aqueous solution (Milli-Q water prepared with Yamato-Millipore WQ501; $3.0 \mathrm{~cm}^{3}$, adjusted to pH 3 by addition of hydrochloric acid) containing $30 \mathrm{mg}$ of a photocatalyst was studied under monochromatic irradiation under air. The suspensions were stirred in the dark for $2 \mathrm{~h}$ to reach an adsorption equilibrium and were then subjected to monochromatic irradiation for $30 \mathrm{~min}$ in the range of 290 - $680 \mathrm{~nm}$ using a diffraction grating type illuminator (Jasco CRM-FD) equipped with a 300-W xenon lamp (Hamamatsu Photonics C2578-02). The intensity of irradiation, measured by a Molectron PM5200 laser power meter, was in the range of $1.98-6.52 \times 10^{-8}$ einstein $\mathrm{s}^{-1}$. Since the rate of photocatalytic reactions, especially those including molecular oxygen, is known to depend on the intensity and on the wavelength [31], the light flux should be adjusted to be independent of the wavelength. In the present study, however, the intensity dependence on the wavelength was ignored, so as to avoid an additional error in the measurement of the reaction rate by adjustment of the light flux to its minimum level. Full-width at half-maximum (FWHM) of the monochromatic light was $17 \mathrm{~nm}$ irrespective of wavelength.

\subsection{Product analysis}


The molar amounts of MB before and after irradiation were determined by measuring the absorbance at $664 \mathrm{~nm}$ with a spectrophotometer (Shimadzu MPS-2450). The molar extinction coefficient was determined using a standard MB solution of given concentration. In the case of photocatalytic decomposition of $\mathrm{AcOH}$, an aqueous $\mathrm{AcOH}$ (Wako Pure Chemical) solution was used instead of an $\mathrm{MB}$ solution, and liberated carbon dioxide $\left(\mathrm{CO}_{2}\right)$ was measured by a gas chromatograph (Shimadzu GC-14B) equipped with a flame ionization detector (FID) and a methanizer (Shimadzu MTN-1). Because of the relatively smaller yield of $\mathrm{CO}_{2}$ under monochromatic irradiation, enhancement of FID sensitivity by converting $\mathrm{CO}_{2}$ into methane in the methanizer was required. The irradiation was continued until an almost linear increase in the $\mathrm{CO}_{2}$ amount was observed. The apparent quantum yield ( $\left.\Phi_{\text {app }}\right)$ was calculated as a ratio of the molar rate of consumption of $\mathrm{MB}$ or the generation of $\mathrm{CO}_{2}$ to the flux of incident photons.

\section{Results and discussion}

\subsection{Action spectra of $M B$ decomposition in the UV range}

The action spectra of MB decomposition, shown in Fig. 1, can be interpreted and discussed by dividing them into three parts. In region I (290-400 nm), the action spectra for S- $\mathrm{TiO}_{2}$ and P-25 resemble each other in shape and so does the diffuse reflectance (DR) spectrum of P-25. Since only negligible absorption of $\mathrm{MB}$ was observed, the $\mathrm{MB}$ decomposition in this region can be mainly ascribed to the ordinary band-gap photoexcitation of titania [29]. Most of the photons in this region are absorbed by titania due to the large absorption coefficient, but the value of $\Phi_{\text {app }}$ (e.g., $0.2-0.3 \%$ at $305 \mathrm{~nm}$ ) seems very small. Since the reaction mechanism has not been clarified, we assumed that one photon corresponds to one molecule of $\mathrm{MB}$ decomposition neglecting the radical chain reaction to calculate $\Phi_{\text {appp }}$. It is therefore difficult to evaluate the actual efficiency of electron and hole utilization. This is one of the problems encountered when MB is chosen as a substrate of photocatalytic reaction. 
Such ambiguity in the mechanism of MB reaction has been claimed by Mill and Wang [29]. They pointed out that, even under ultraviolet irradiation where MB photoabsorption may be disregarded, the reaction mechanism is still ambiguous and influenced by the reaction conditions. A notable point is that the activity of $\mathrm{S}-\mathrm{TiO}_{2}$ was comparable to that of P-25 in region I. A slight shift of the action spectrum of $\mathrm{S}-\mathrm{TiO}_{2}$ to shorter wavelength than that of P-25 will be discussed in section 3.4.

\subsection{Action spectra of $M B$ decomposition in the visible range}

In region III (540-680 $\mathrm{nm}$ ), the absorption spectra show that MB, but neither of the photocatalysts, can absorb photons. The DR spectrum of P-25 suspension in an aqueous MB solution (Fig. 1(b)) was broadened, especially at shorter wavelengths, in comparison with the absorption spectrum of an aqueous MB solution. The spectrum might include contribution of adsorbed or free (dissolved) aggregated MB molecules, but at present we cannot discriminate them. The shorter wavelength peak at $\sim 600 \mathrm{~nm}$ is attributable to MB dimer [29], but the absorption tail of 400-600 nm was not observed in a solution, suggesting the aggregation of $\mathrm{MB}$ on the surface of $\mathrm{TiO}_{2}$. This DR spectrum clearly resembles the action spectra of $\mathrm{S}-\mathrm{TiO}_{2}$ and P-25, suggesting the contribution of photoabsorption by MB. A fluctuating shape of the action spectra in this region may be attributed to sizable errors in the measurement of $\mathrm{MB}$ concentration. An apparent quantum efficiency of $5 \times 10^{-5}$ corresponds to a change of $\sim 0.01$ in the absorbance of measured diluted solutions, and such a problem in the determination of a small change in the substrate concentration seems to be another disadvantage of the use of MB as a probe molecule. We note, however, that a sharp dip at $~ 635 \mathrm{~nm}$ was observed in both suspensions, suggesting a difference in the photosensitizing activity of MB of different configurations, as discussed in the following paragraph. At present we have no additional experimental results on the structure of MB sensitizing the reaction, but we believe that we have been able to show the decomposition of MB induced by photoabsorption of MB itself, but not $\mathrm{TiO}_{2}$, in this wavelength region. 
A possible mechanism is electron injection from photoexcited MB molecules to $\mathrm{TiO}_{2}$, leading to reduction of molecular oxygen and oxidative decomposition of the electron-deficient MB, i.e., photosensitization. Such photosensitization by MB has already been suggested [29, 32-34], but contribution of photoinduced degradation of MB to the overall rate of reaction could not be estimated quantitatively, and the action spectrum analysis in the present study seems to be the only possible method for such evaluation. We note that this photoreaction may hardly be influenced by the real photocatalytic activity of $\mathrm{TiO}_{2}$ but that the rate might depend on the nature of $\mathrm{TiO}_{2}$ particles. Namely, the physical properties of $\mathrm{TiO}_{2}$ might influence the rate, because the MB photoreaction may proceed mainly through adsorption and electron injection. Thus, we conclude that MB is an inappropriate substrate for a photocatalytic activity test at least when the radiation in region III is illuminated.

\subsection{Action spectra of MB decomposition in the mid-wavelength region}

The remaining region, region II (400-540 nm), exhibits intermediate behavior, reflecting a marked difference in the DR spectra of $\mathrm{S}-\mathrm{TiO}_{2}$ and P-25, as well as tailing of $\mathrm{MB}$ absorption. The higher rate of $\mathrm{S}-\mathrm{TiO}_{2}$ is attributable to its larger absorption, and its almost plateau curve seems to be a result of the combination of the contributions to the absorption by both $\mathrm{TiO}_{2}$ and $\mathrm{MB}$. On the assumption that the photocatalytic activity of P-25 in this region and comparable contributions of direct MB photoreaction in both suspensions are negligible, the appreciable visible-light sensitizing ability of $\mathrm{S}^{-\mathrm{TiO}_{2}}$ can be assigned mainly to the photocatalytic activity of S- $\mathrm{TiO}_{2}$. Thus, it seems difficult to elucidate the real photocatalytic activity, using MB as a substrate, also in this wavelength region.

\subsection{Action spectra of AcOH decomposition}

Figure 2 shows the action spectra for oxidative decomposition of $\mathrm{AcOH}$ in an aerated aqueous solution. Since the stoichiometry in this photocatalytic reaction system is known to be $\mathrm{CH}_{3} \mathrm{COOH}+2 \mathrm{O}_{2}=2 \mathrm{CO}_{2}+2 \mathrm{H}_{2} \mathrm{O}$, we ignored possible radical chain mechanism and assumed 8 holes and electrons are required when $\Phi_{\text {app }}$ was calculated. The detection of $\mathrm{CO}_{2}$ in 
1 a low concentration requires additional equipments (a methanizer), but the use of AcOH as a

2 probe molecule has several merits other than that it has no visible-light absorption: 1) The

3 reaction is relatively simple, producing $\mathrm{CO}_{2}$ with fewer intermediates. 2) Due to the acidity of

4 its solution, liberated $\mathrm{CO}_{2}$ is removed to the gas phase. 3) The product $\left(\mathrm{CO}_{2}\right)$ can be analyzed

5 separately, not by photoabsorption spectroscopy. Although photoabsorption spectroscopy is a

6 convenient method, it is not applicable, in principle, unless the concentrations and extinction

coefficients of all other components (intermediates) included in the system are precisely determined.

The spectra were rather simple; both $\mathrm{S}-\mathrm{TiO}_{2}$ and $\mathrm{P}-25$ exhibited comparable photocatalytic activity in region I. The lower activity of the former may be ascribed to the enhanced recombination of photoexcited electrons and holes in this region, since dopants also acted as a recombination center. A slight shorter-wavelength shift of the spectra of $\mathrm{S}^{-\mathrm{TiO}_{2}}$ is also attributable to the enhanced recombination in the near band-gap wavelength. Only $\mathrm{S}-\mathrm{TiO}_{2}$ showed an appreciable response in region II, and negligible photoinduced reaction occurred on both powders in region III. A plausible interpretation of these results is that the present $\mathrm{S}-\mathrm{TiO}_{2}$ has real photocatalytic activity under visible irradiation that corresponds to the absorption in this region, as suggested by the above-mentioned MB reaction.

\section{Conclusion}

The results indicate that there are two significant problems in the photocatalytic activity test. One is the inadequacy of $\mathrm{MB}$ as a probe molecule for semiconductor photocatalysis, since the photoinduced reaction by MB photoabsorption may mislead into believing that a given semiconductor material has visible-light photocatalytic activity. Dyes other than MB [35] should also be examined for their suitability as a probe molecule. The other problem is the photoirradiation systems for the activity test. As above, action spectrum analyses enable us to discriminate the origin of photoresponse by checking the wavelength 
1 dependence. However, when the samples are irradiated in MB solutions, for example, with a

2 set of optical cut-off filters that transmit light of a wavelength longer than a given wavelength,

as customarily employed, the results cannot be a proof of visible-light sensitizing ability, i.e., real photocatalytic activity.

In summary, the use of transparent substrates in the region of working wavelengths is strongly recommended, if at all possible, in a photocatalytic activity test for photocatalysts and for action spectrum analysis. By using the preferred test system, the present $\mathrm{S}-\mathrm{TiO}_{2}$ has been proved really photoactive in the visible region, at least for the decomposition of $\mathrm{AcOH}$ into $\mathrm{CO}_{2}$. However, the present finding does not guarantee the visible-light activity for other frequently-used substrates such as acetone or toluene, which need careful individual examination.

\section{Acknowledgments}

The authors acknowledge financial support by a Grant-in-Aid for Scientific Research on Priority Areas (417) (No. 17029001) from the Ministry of Education, Culture, Sports, Science and Technology (MEXT) of Japan.

\section{References}

[1] M. Kaneko, I. Okura (Eds.), Photocatalysis: Science and Technology, Kodansha-Springer, Tokyo, 2002.

[2] A.G. Agrios, P. Pichat, J. Appl. Electrochem. 35 (2005) 655.

[3] W. Choi, A. Termin, M.R. Hoffmann, J. Phys. Chem. B 98 (1994) 13669.

[4] T.J. Kemp, R.A. McIntyre, Polym. Deg. Stab. 91 (2006) 165.

[5] H. Kisch, G. Burgeth, W. Macyk, Adv. Inorg. Chem. 56 (2004) 241.

[6] P.A. Sant, P.V. Kamat, Phys. Chem. Chem. Phys. 4 (2002) 198.

[7] L. Wu, J.C. Yu, X. Fu, J. Mol. Catal. A: Chem. 244 (2006) 25. 
1 [8] J. Gautron, P. Lemasson, J.F. Marucco, Faraday Disc. 70 (1980) 81.

2 [9] T. Ihara, M. Miyoshi, M. Ando, S. Sugihara, Y. Iriyama, J. Mater. Sci. 36 (2001) 4201.

3 [10] S. Sato, R. Nakamura, S. Abe, Appl. Catal. A: Gen. 284 (2005) 131.

[11] R. Asahi, T. Morikawa, T. Ohwaki, K. Aoki, Y. Taga, Science 293 (2001) 269.

[12] S. Sakthivel, M. Janczarek, H. Kisch, J. Phys. Chem. B 108 (2004) 19384.

[13] T. Matsumoto, N. Iyi, Y. Kaneko, K. Kitamura, Y. Takasu, Y. Murakami, Chem. Lett. 33 (2004) 1508.

[14] H. Irie, S. Washizuka, Y. Watanabe, T. Kako, K. Hashimoto, J. Electrochem. Soc. 152 (2005) E351.

[15] Y. Nosaka, M Matsushita, J. Nishino, A. Nosaka, Sci. Tech. Adv. Mat. 6 (2005) 143.

[16] W. Ho, J.C. Yu, S. Lee, Chem. Commun. 10 (2006) 1115.

[17] S.U.M. Khan, M. Al-Shahry, W.B. Ingler, Jr., Science 197 (2002) 2243.

[18] S. Sakthivel, H. Kisch, Angew. Chem. Int. Ed. 42 (2003) 4908.

[19] Y. Li, D.S. Hwang, N.H. Lee, S.J. Kim, Chem. Phys. Lett. 404 (2005) 25.

[20] W. Zhao, W. Ma, C. Chen, J. Zhao, Z. Shuai, J. Am. Chem. Soc. 126 (2004) 4782.

[21] T. Umebayashi, T. Yamaki, S. Tanaka, K. Asai, Chem. Lett. 32 (2003) 330.

[22] T. Ohno, T. Mitsui, M. Matsumura, Chem. Lett. 32 (2003) 364.

[23] T. Ohno, M. Akiyoshi, T. Umebayashi, K. Asai, T. Mitsui, M. Matsumura, Appl. Catal. A: Gen. 265 (2004) 115.

[24] H. Liu, L. Gao, J. Am. Ceram. Soc. 2004, 87, 1582.

[25] D. Li, N. Ohashi, S. Hishita, T. Kolodiazhnyi, H. Haneda, J. Solid State Chem. 178 (2005) 3293.

[26] D. Noguchi, Y. Kawamata, T. Nagatomo, J. Electrochem. Soc. 152 (2005) D124.

[27] M. Horio, Nihon Gakujutsu Kyokai Hokoku, 12 (1937) 204 (in Japanese).

[28] R.W. Matthews, Wat. Res. 25 (1991) 1169.

[29] A. Mills, J. Wang, J. Photochem. Photobiol. A: Chem. 127 (1999) 123. 
1 [30] T. Torimoto, N. Nakamura, S. Ikeda, B. Ohtani, Phys. Chem. Chem. Phys. 4 (2002) 5910.

[31] T. Torimoto, Y. Aburakawa, Y. Kawahara, S. Ikeda, B. Ohtani., Chem. Phys. Lett. 392

4 (2004) 220.

5 [32] X. Li, P. Fitzgerald, L. Bowen, Wat. Sci. Tech. 26 (1992) 367.

6 [33] W.S. Kuo, P.H. Ho, Chemosphere 45 (2001) 77.

7 [34] D. Chatterjee, A. Mahata, J. Photochem. Photobiol. A: Chem. 153 (2002) 199.

8 [35] I.K. Konstantinou, T.A. Albanis, Appl. Catal. B: Environ. 49 (2004) 1. 


\section{Figure Captions}

2 Fig. 1. Action spectra of $\mathrm{MB}$ decomposition on (A) $\mathrm{S}-\mathrm{TiO}_{2}$ and (A') $\mathrm{P}-25$ in (a) overall 3 region and (b) visible region; DR spectra of (B) $\mathrm{S}-\mathrm{TiO}_{2}$ and (B') P-25; (C) DR spectrum of 4 adsorbed MB.

5

6 Fig. 2. Action spectra of $\mathrm{AcOH}$ decomposition on (A) $\mathrm{S}-\mathrm{TiO}_{2}$ and (A') P-25 in (a) overall 7 region and (b) visible region. 
1

Figures

2

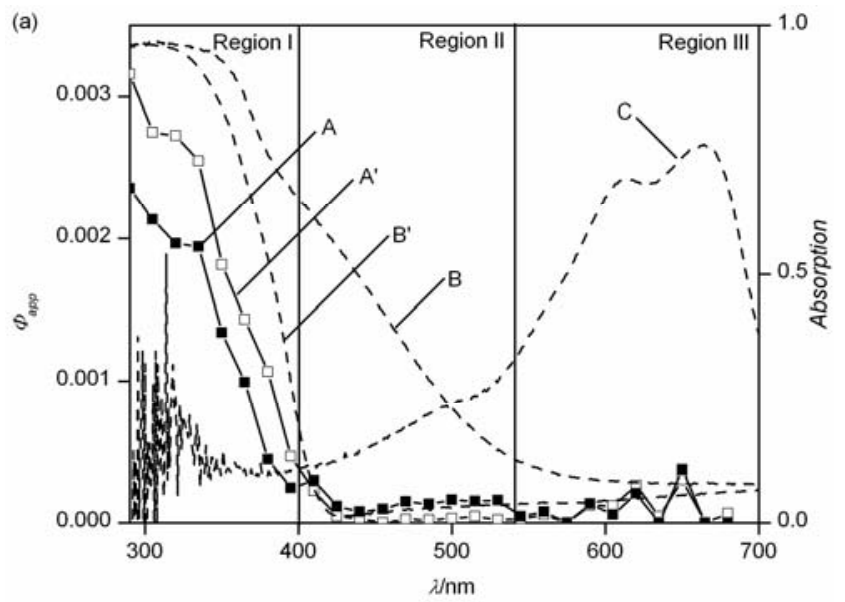

3

6

7

8

9

10

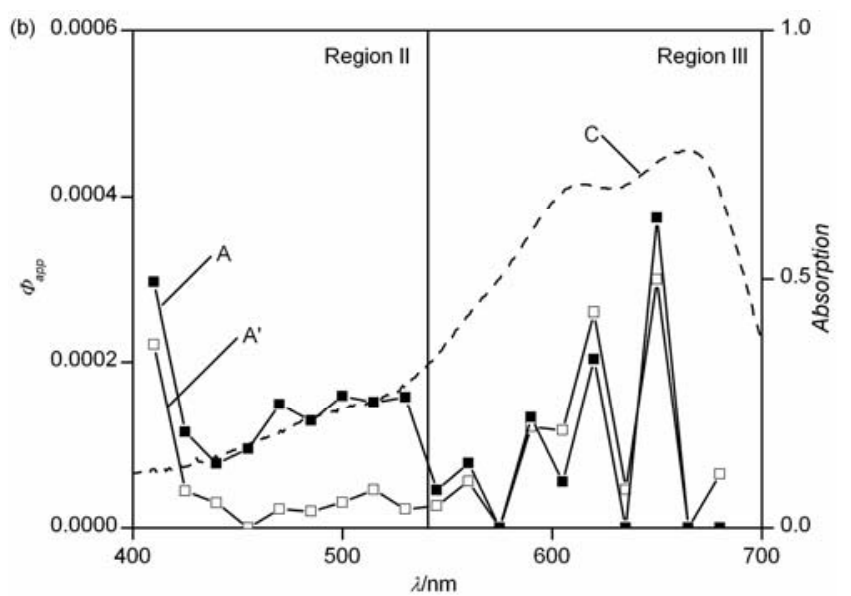

Figure 1

(

9 

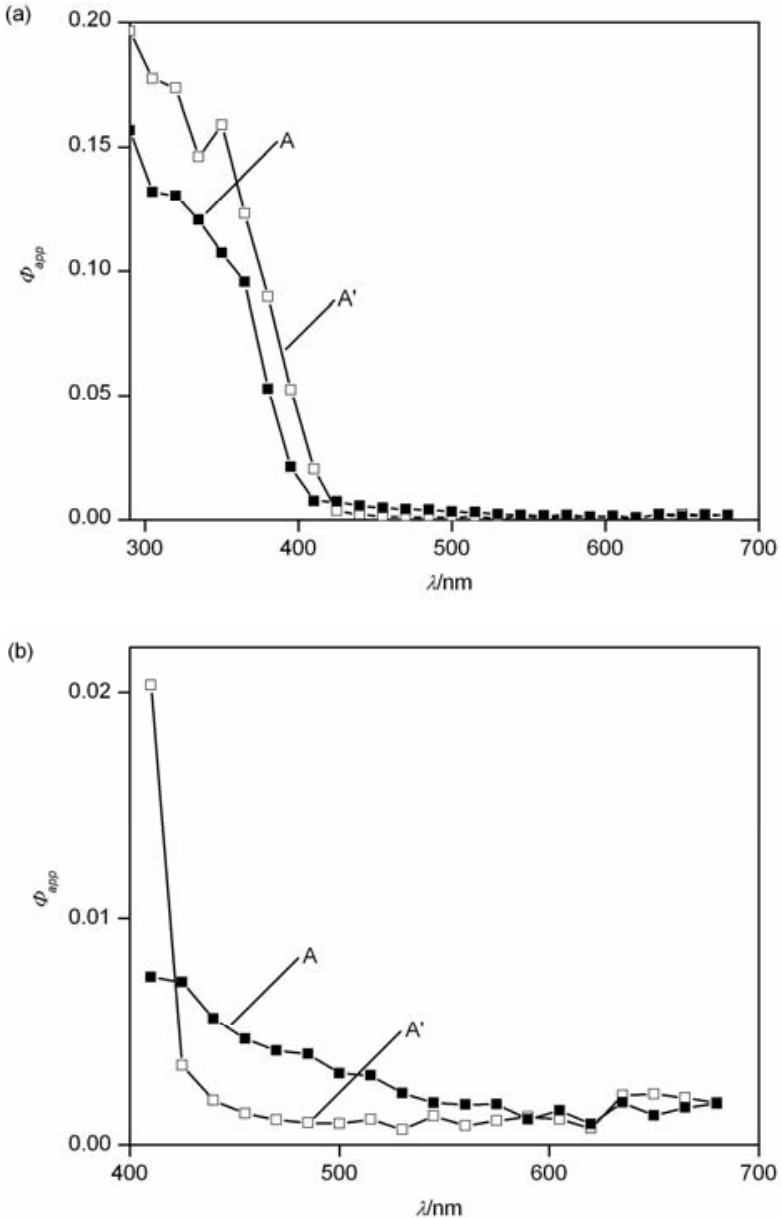

Figure 2 


\section{Graphical Abstract}

2 Action spectrum analysis revealed that the mechanism of methylene blue (MB)

3 decomposition on doped and non-doped titania included both titania photocatalysis and MB

4 photosensitization and their extent depended on the excitation wavelengths, thus indicating

5 that dye with photosensitizing ability is not an appropriate substrate, especially for 6 visible-light activity evaluation.

7

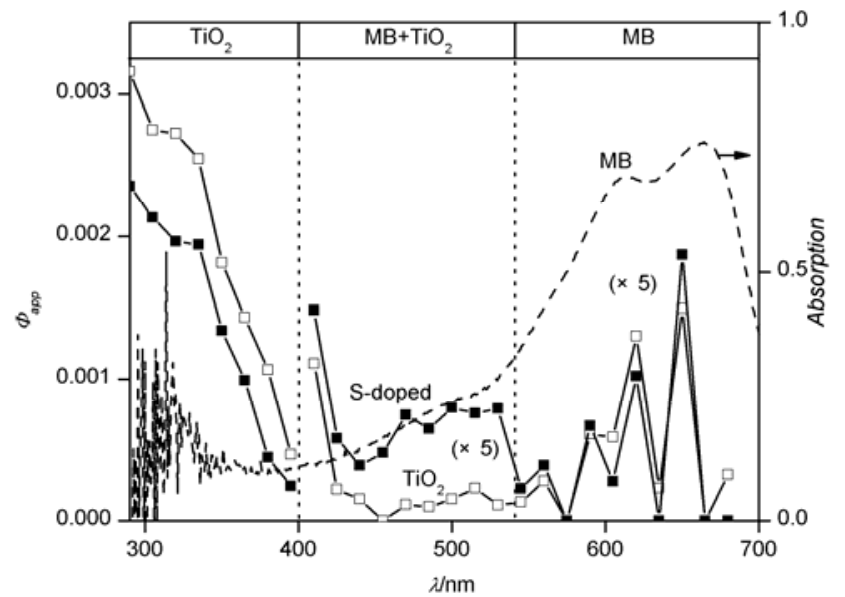

8

9 